\title{
Aberrant Coronary Vein as a Hepatopetal Collateral Pathway for Extrahepatic Portal Venous Obstruction
}

\author{
Masao Hashimoto Nobutaka Umekita \\ Department of Surgery, Tokyo Metropolitan Bokutoh General Hospital, Tokyo, Japan
}

The coronary vein normally joins the portal vein, the splenic vein, or the confluence of the two. In contrast, persisting anastomoses among the foregut venous plexus or omphalomesenteric veins result in various venous anomalies, including the aberrant coronary vein, which originates from the lesser curvature of the stomach, moves through the lesser omentum and drains directly into the left portal system.

Computed tomography of a 50-year-old man revealed a low density mass, $10 \mathrm{~cm}$ in diameter, in the retroperitoneal space behind the pancreas head. A thick vein from the lesser curvature that drained into the left lateral sec- tor of the liver was identified as an aberrant coronary vein (fig. 1). A superior mesenteric arterioportogram revealed portal vein obstruction, resulting in portal blood flowing back to the right gastroepiploic and splenic veins. Venous blood of the lesser curvature then drained into the left portal system via the aberrant coronary vein (fig. 2).

Cavernous transformation of the portal vein is a typical finding when the portal vein is obstructed with or without the intrahepatic branch. An aberrant coronary vein can be a hepatopetal collateral pathway when the portal vein is obstructed as in the present case.
Fig. 1. Preoperative enhanced computed tomography. A thick vein (arrow) from the lesser curvature drained into the left lateral sector of the liver and was identified as an aberrant coronary vein.

Fig. 2. Preoperative angiogram. A superior mesenteric arterioportogram revealed portal vein obstruction, resulting in portal blood flowing back to the right gastroepiploic (arrow head) and splenic (thin arrow) veins. Venous blood of the lesser curvature then drained into the left portal system via the aberrant coronary vein (thick arrow).
1

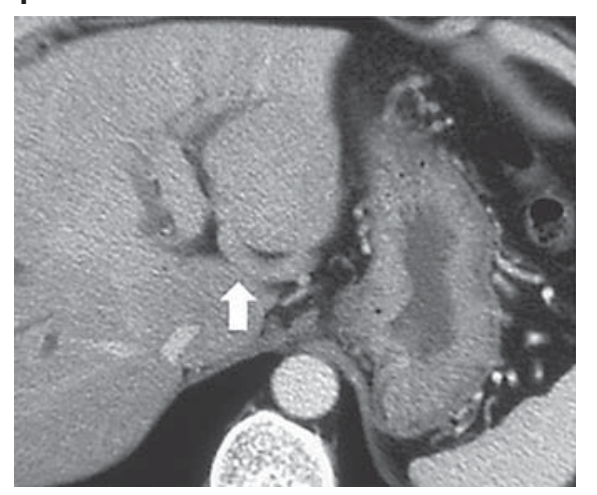

2

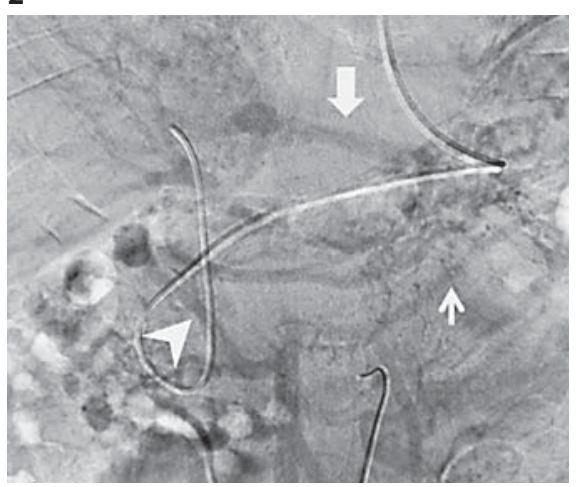

\section{KARGER}

Fax +4161306 1234 E-Mail karger@karger.ch www.karger.com
(C) 2008 S. Karger AG, Basel

0253-4886/08/0254-0310\$24.50/0

Accessible online at:

www.karger.com/dsu
Masao Hashimoto, MD

Department of Surgery, Tokyo Metropolitan Bokutoh General Hospital

4-23-15 Kohtohbashi, Sumida-ku

Tokyo 130-8575 (Japan)

Tel. +81 33633 6151, Fax +81 33633 6173, E-Mail hashimom-tky@umin.ac.jp 